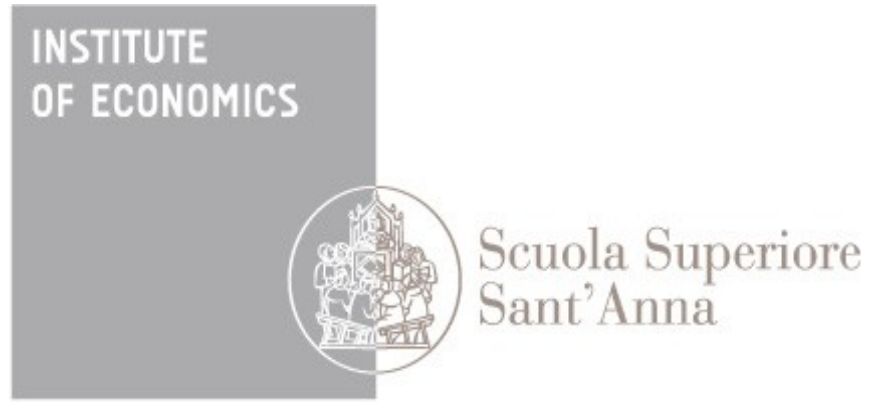

LEM | Laboratory of Economics and Management

Institute of Economics

Scuola Superiore Sant'Anna

Piazza Martiri della Libertà, 33 - 56127 Pisa, Italy ph. +3905088.33 .43$

institute.economics@sssup.it

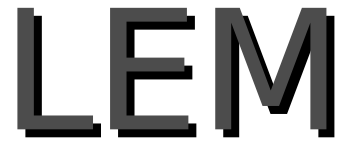

Working Paper Series

\title{
Tech on the ROC: Export Threshold and Technology Adoption Interacted
}

Stefano Costa ${ }^{a}$

Federico Sallusti a

Claudio Vicarelli a

Davide Zurlo ${ }^{a}$

a Italian National Institute of Statistics, Rome, Italy. 


\title{
Tech on the ROC:
}

\section{Export Threshold and Technology Adoption Interacted}

\author{
Stefano Costa*, Federico Sallusti*, Claudio Vicarelli*, Davide Zurlo*
}

NOVEMBER 2019

\begin{abstract}
This paper analyses the potential mismatch between the conditions required for a manufacturing firm to become exporter and the pattern of technology adoption within the industry. The 'export threshold', which is estimated using the ROC methodology, is the minimum combination of productivity and 'economic size' (a broader measure of firm size) that firms need to achieve in order to access export markets. To consider the pattern of technology adoption we also estimate a 'technology line'. The relative positioning of the 'technology line' and the export threshold generates a new taxonomy of firms allowing for better policies for internationalization.
\end{abstract}

\section{JEL code: F14, L60, L11, O14}

Keywords ROC analysis, export threshold, technology adoption, extensive margin of exports

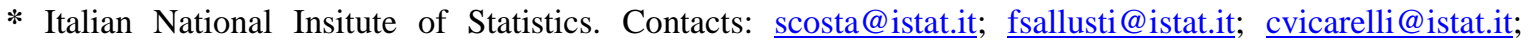
zurlo@istat.it.

We are grateful to Matteo Bugamelli, Luca De Benedictis, Sergio De Nardis, Andrea Linarello, Fabrizio Traù, the participants in the 2019 Annual Conference of the Italian Economists Association and the participants in the first Seminar of ISTAT Thematic Research Laboratories for their helpful observations. The opinions expressed in this work are those of the authors and do not necessarily represent the view of ISTAT. 


\section{Introduction}

Export activity is essential for the competitiveness of firms and, on a macro level, for the economic growth of countries. Hence, policies aimed at increasing firms' participation in international markets, both in terms of intensive and extensive margins, have been gaining prominence on national economic agendas This, in turn, highlights the importance of being able to detect the firm-level determinants of export, i.e. the minimum requirements firms have to meet in order to become exporters.

In a previous paper (Costa et al., 2019), we applied the Receiver Operating Characteristics (ROC) analysis to develop a new methodology for the estimation of the 'export threshold', i.e. the minimum combination of productivity and 'economic size' (a broad measure of firm size composed of employment, age, turnover and capital intensity) corresponding to the transition from non-exporter to exporter status. This enables us to position each firm according to its distance from the threshold.

In this paper, we enhance the analysis by explicitly taking into account the technological level of firms. In particular, we analyse the potential mismatch between the conditions required for a firm to become an exporter and the pattern of technology adoption within the industry. This permits to design a map of the business system that is particularly useful from a policy-making point of view as it informs more targeted policies aimed at boosting firm participation in foreign markets.

The possibility of a mismatch between the sorting of firms in terms of export premia and technological intensity has been widely studied in recent literature focusing on firm heterogeneity. Among the most influential works, Bustos (2011) developed a model with heterogeneous firms where exporters can upgrade their technology after entering foreign markets, so that productivity differentials cluster firms in three groups: high-technology exporters, low-technology exporters, and low-technology domestics. It follows that some exporting firms (i.e. new exporters but also firms that were already exporting) are not more technology intensive than non-exporters, even though they can upgrade their technology faster once they enter the export markets and/or when variable trade costs decrease (i.e. due to a fall in tariffs). In a similar vein, using data on the Canadian business system, Lileeva and Trefler (2010) show that heterogeneity in firms' investing choices can affect the productivity-export relationship through technology adoption. Analogous results 
are found for the U.S. (Bernard et al., 2003), Spain (Delgado et al., 2002), and Germany (Bertschek et al., 2016).

The empirical literature has largely analyzed the relationship between export, productivity, and size (see Wagner, 2012 and ISGEP, 2008 for detailed surveys). The existence of some export thresholds characterizes all theoretical works on firm heterogeneity originating from the seminal paper of Melitz (2003), where only firms above a minimum productivity level are able to sell abroad (Melitz and Ottaviano, 2008; Chaney, 2008; Bernard et al., 2011). However, from an empirical perspective, several works have showed that in many countries, firm productivity distributions of exporters and non-exporters may overlap, implying that enterprises might not export even though their productivity levels would enable them to (i.e. they are above the productivity threshold). ${ }^{1}$

Firm size also is relevant explain their ability to export, with larger size loosening the constraint represented by sunk costs. Indeed, empirical studies have found a direct relationship between export and size: exporters tend to be larger than non-exporters (Wagner 1995; Majocchi et al., 2005; Máñez-Castillejo et al., 2010). This raises important questions about the sources of export premia and, more specifically, whether and to what extent such sources could be related to the size of firms. Internal sources may include managerial talent, quality of inputs, information technology, R\&D, learning by doing, and innovation (Syverson, 2011). Small and large firms may differ in terms of access to these sources (Leung et al., 2008). External factors such as regulation and access to financing could also be responsible for heterogeneity between small and large firms (Tybout, 2000).

The rest of the paper is organized as follows: Section 2 presents a description of the dataset and empirical strategy. Section 3 illustrates the ROC methodology for the estimation of the export threshold. Section 4 introduces the technology line. Section 5 shows the new taxonomy resulting from the interaction between the export threshold and the technology line. Section 6 concludes.

\footnotetext{
${ }^{1}$ See, among others, Castellani and Zanfei (2007) for the Italian case, Wagner (2007) and Schröder and Sørensen (2012) for two comprehensive surveys. Moreover, others (Schröder and Sørensen, 2012; Geishecker et al., 2017) have shown that the mismatch between Melitz's theory and empirical evidence is actually linked to the definition of productivity.
} 


\section{Data}

The main statistical source used as basis for this work is the business register "Frame-Sbs" for 2016. Released annually by ISTAT since 2011, it provides information on the structure (e.g. number of employees, business sector, location, age, belonging to a group) and the main economic variables (e.g. value of production, turnover, value added, labour cost) for the whole population of about 4.4 million of Italian firms.

This database is then integrated with Custom Trade Statistics, a census dataset reporting the values of imports, exports, and trade balance with both EU (intra-EU trade) and nonEU operators (extra-EU trade) of each Italian firm.

Table 1. The sample: Industry classification and firms' characteristics

\begin{tabular}{|c|c|c|c|c|c|c|}
\hline Industry & $\begin{array}{l}\text { Nace Rev. } 2 \text { code } \\
\text { included }\end{array}$ & $\begin{array}{c}\text { Number of } \\
\text { firms }\end{array}$ & Share of firms & $\begin{array}{c}\text { Share of value } \\
\text { added }\end{array}$ & $\begin{array}{c}\text { Share of } \\
\text { employees }\end{array}$ & $\begin{array}{l}\text { Share of } \\
\text { exports }\end{array}$ \\
\hline Food and beverage & 10,11 & 39,356 & 18.9 & 12.1 & 12.9 & 7.9 \\
\hline Textile & 13 & 8,274 & 4.0 & 2.8 & 3.4 & 2.6 \\
\hline Wearing apparel & 14 & 11,957 & 5.7 & 3.3 & 4.8 & 4.1 \\
\hline Leather & 15 & 8,634 & 4.1 & 3.3 & 4.0 & 5.1 \\
\hline Wood & 16 & 15,410 & 7.4 & 1.7 & 2.8 & 0.5 \\
\hline Paper and print & 17,18 & 12,927 & 6.2 & 4.4 & 4.7 & 2.3 \\
\hline Chemicals and pharmaceutics & 20,21 & 3,679 & 1.8 & 9.6 & 5.2 & 13.3 \\
\hline Rubber and plastic & 22 & 7,732 & 3.7 & 5.6 & 5.4 & 5.0 \\
\hline Non metalic minerals & 23 & 11,766 & 5.6 & 4.3 & 4.6 & 2.8 \\
\hline Metals & 24,25 & 46,319 & 22.2 & 16.5 & 18.6 & 13.6 \\
\hline Electronics & 26,27 & 9,082 & 4.4 & 7.8 & 7.3 & 7.8 \\
\hline Machinery & 28 & 18,429 & 8.8 & 16.3 & 14.5 & 20.4 \\
\hline Automotive & 29,30 & 3,269 & 1.6 & 9.5 & 8.1 & 12.0 \\
\hline Furniture & 31 & 11,793 & 5.7 & 2.8 & 3.9 & 2.5 \\
\hline Total & & 208,627 & 100.0 & 100.0 & 100.0 & 100.0 \\
\hline
\end{tabular}

Source: Authors' calculation on ISTAT data.

In order to focus on relevant business units, some restrictions are imposed. Considering the extreme fragmentation of the Italian business system - where in 2016 the average firm size was less than 4 workers, and the enterprises with just one worker accounted for over $50 \%$ of total firms and $12 \%$ of total employment - we limit our analysis to firms with 'economic relevance'. Consequently, we consider firms that have positive value added, no less than 1 employee, and positive consumption of fixed capital. Moreover, we only retain firms operating in manufacturing (excluding Tobacco, Refined petroleum products, 
Maintenance and repair, and Other manufacturing), ${ }^{2}$ which in 2016 accounted for $83 \%$ of Italian export. Finally, we rule out, from the set of the exporters, irregular and one-off exporting firms, so as to consider only the 'stable exporters', namely those exporting on a regular basis over the three-year period 2014-2016. ${ }^{3}$ The final dataset includes 208,627 firms, accounting for about $54 \%$ of manufacturing firms, $85 \%$ of the workforce, $93 \%$ of value added, and $84 \%$ of exports. Table 1 reports industry composition and the main information about the strata of analysis.

\section{ROC methodology and export threshold}

\subsection{The basics of the ROC analysis}

Applying the methodology developed in our previous work (Costa et al., 2019), we estimate the export threshold on the basis of the joint application of the Receiver Operating Characteristics (ROC, hereinafter) analysis and Youden's (1950) J index. This approach permits to pinpoint a cut-off on whose basis to classify a set of observations (firms) with respect to a binomial variable of interest (in our case: the exporter status) along the distribution of a variable (in our case: productivity-size combination).

The application of the ROC analysis is quite new in Economics. To the best of our knowledge, so far this methodology has only been used to test the accuracy of business cycle classification made by the Business Cycle Dating Committee of the National Bureau of Economic Research (Berge and Jordà, 2011) and in credit risk literature (Khandani et al., 2010). However, it has been widely adopted in medicine (Lusted, 1960), and it is now a common standard of evaluation of medical and psychological tests (Pepe, 2003). Furthermore, ROC methodology is used in machine learning (Majnik and Bosnić, 2013), and natural science (Warnock and Peck, 2010).

\footnotetext{
2 The exclusion of Tobacco and Refined petroleum products is due to the peculiar characteristics of these activities (regulation and monopoly). Maintenance and repair has been excluded because of its high content of services. Other manufacturing has been excluded because it includes miscellaneous activities (see NACE Rev. 2 Classification).

${ }^{3}$ There is no universally agreed definition of 'stable exporter', except that, for a firm to be defined as such, it has to be exporting on a regular basis over a specified (more than a year) period. We preferred the 20142016 time span because it is more homogeneous from a business cycle point of view, as it fully covers the Italian post-recession period.
} 
According to Fawcett (2005), classification models (or classifiers) can give four possible outcomes: True positive (TP), False positive (FP), True negative (TN), False negative $(\mathrm{FN})$.

The validity of a classifier can be measured based on two main metrics: Sensitivity and Specificity. Sensitivity represents the probability of detecting true positives. Specificity is the probability of detecting true negatives. This latter is usually considered in its reciprocal expression (1-Specificity), which measures the probability of false positives.

Once a classifier is applied, the ROC curve displays the position of each observation in the space of Sensitivity and 1-Specificity (Figure 1), showing the trade-off between the probability of detecting true positives and the probability of false positives across all possible cut-offs (Kumar and Indrayan, 2011).

Figure 1. The ROC curve

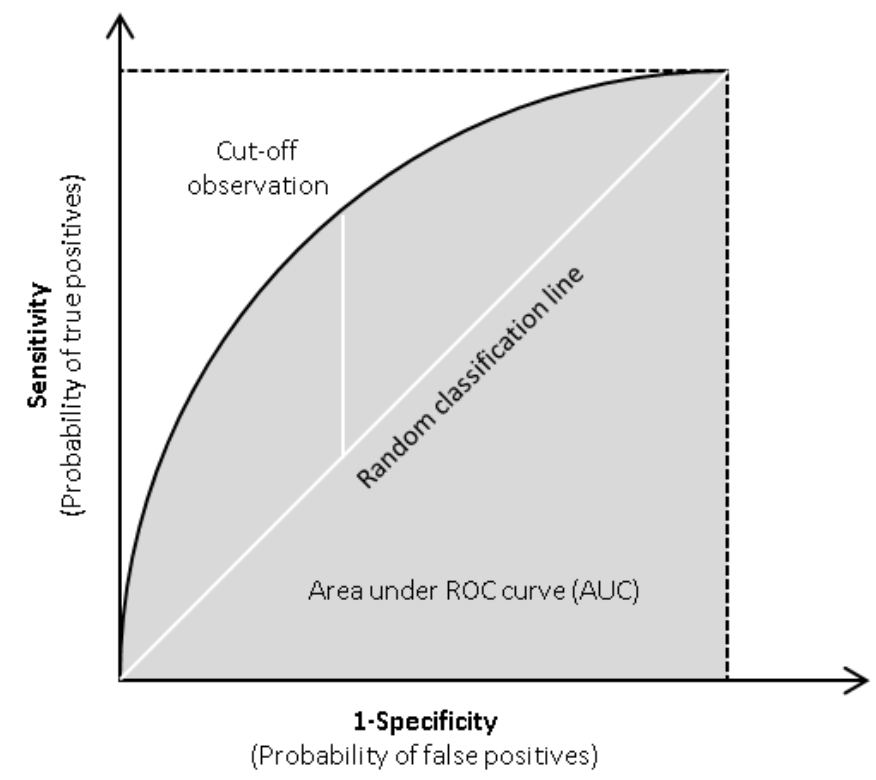

The area under the ROC curve (AUC, grey portion in Figure 1) provides a measure of the extent to which the clustering obtained by the model is more efficient than a pure random classification (the $45^{\circ}$ line). In this respect, the AUC criterion is largely used to measure the goodness of fit of logit models, and to define the relative relevance of a set of variables in determining the overall logistic distribution of probability. 
In order to single out, along the ROC curve, the observation that most efficiently discriminates between positives and negatives ( $\widehat{\mathrm{Cu}} \mathrm{t})$, the following equation is used:

$$
\widehat{\text { Cut }}=h * \text { Sensitivity }-(1-h) *(1-\text { Specificity })
$$

where $h$ and $(1-h)$ represent the relative weights to manage the trade-off between true and false positives. By setting up $h=0.5$, we opt for a "neutral" selection between the two outcomes. ${ }^{4}$ In doing so, Equation [1] turns out to be equal to Youden's (1950) $\mathrm{J}$ index:

$$
(\text { Sensitivity }+ \text { Specificity }-1)
$$

Youden's $J$ - which identifies the observation that maximizes equation [2] and, consequently, the vertical distance between ROC curve and the $45^{\circ}$ line (see Figure 1 ) - is the most commonly used criterion for detecting optimal cut-offs. ${ }^{5}$ Moreover, the $J$ index, which implies a "neutral" choice between false positives and negatives, is all the more suitable for our purposes, because we have no a priori bias in dealing with the trade-off. ${ }^{6}$

\subsection{Definition of the "export threshold"}

As in our previous work, in order to apply the ROC analysis to the identification of the export threshold, we firstly estimate the probability to export of the $i$-th firm in the $h$-th industry based on the following logit model:

\footnotetext{
${ }^{4}$ Values of $h>0.5$ (i.e., finding true positives is more relevant than avoiding false positives) would correspond to a 'liberal' selection, which assigns positive classification even in the presence of weak evidence. Conversely, setting up $h<0.5$ (i.e., detecting true positives is less relevant than avoiding false positives) would correspond to a "conservative" selection, which assigns positive classifications only in presence of strong evidence.

${ }_{5}^{5}$ Beside the $J$ index, two other criteria are used to find an optimal threshold point along a ROC curve: $a$ ) the minimization of the distance from the $(0,1)$ point; $b)$ the cost minimization, which considers several types of costs, e.g. for correct and false classification, for further investigation etc., but it is rarely used due to its assessment difficulty.

${ }^{6}$ The best cut-off depends on whether one needs to maximize sensitivity at the expense of 1 -specificity or vice-versa. This often happens in medicine. The first case leads to a test that is maximal sensitive (i.e. correctly identifying diseased people at the expense of a high number of false positives). The second case generates a test that is better at ruling out the disease. The Youden's $J$ maximizes both.
} 


$$
\operatorname{Prob}(\text { Export }=1 \mid X)_{h, i}=\Lambda(\alpha X)_{h, i}
$$

where $\Lambda$ is the cumulative distribution of the logistic function, $\alpha$ is the estimated parameter, and $X$ is the covariate.

Once estimates have been obtained, we use Youden's $J$ to identify the cut-off observation in the $h$-th industry, thus also determining the value of the covariate representing the threshold:

$$
X_{h}^{e}=X_{h, c}
$$

where $c$ is the cut-off (i.e. the export threshold firm).

Consequently, each firm can be classified as exporter or non-exporter according to whether it lays above or below this threshold.

In particular, the export threshold is defined over a combination $\left(\mathrm{Z}_{h}^{e}\right)$ of productivity and economic size $\left(\text { where } \mathrm{X}_{h}^{e}=\mathrm{Z}_{h}^{e}\right)^{7}$

The $Z$ indicator is derived from a three-step procedure. In the first step, for each industry, the economic size is defined, applying a factor analysis over four size-related variables: number of workers; turnover; consumption of fixed capital; age (in terms of number of months from the date of inclusion in the Italian Business Register). For each firm in a given industry, economic size is thus obtained from the linear combination of the four variables as resulting from the first (rotated) auto-vector.

In the second step, the following logit model is estimated for the $h$-th industry:

\footnotetext{
${ }^{7}$ In Costa et al. (2019), we tested two alternative models: a pure sales model (S-model, where X $=$ Sales), in which the export threshold is defined over the value of firms' turnover, and a pure productivity model $(\pi$ model, where $\mathrm{X}=$ Productivity), in which the export threshold is defined over the value of labour productivity (value added-per-worker). Both $S$-model and $\pi$-model have been proved to be consistent with Melitz's theory (Geishecker et al., 2017). Fitting tests showed that the $Z$-model we used in this work outperforms the other two.
} 


$$
\operatorname{Prob}\left(\text { Exporter }_{i}=1 \mid S_{i}, \pi_{i}, G_{i}, I_{i}\right)=\Lambda\left(\alpha_{1} S_{i}+\alpha_{2} \pi_{i}+\alpha_{3} G_{i}+\alpha_{4} I_{i}\right)
$$

where $\Lambda$ is the cumulative distribution of the logistic function, $\alpha_{j}$ are estimated parameters, $S$ is the economic size, $\pi$ is the productivity (expressed in terms of standardised value added-per-worker), $G$ is a set of dummies indicating the location of firms, ${ }^{8}$ and $I$ is a set of dummies referring to NACE 4-digit levels of economic activity.

In the third step, the estimated coefficients of productivity and economic size from equation [5] are used to obtain, for each industry, the composite indicator $Z_{h, i}^{e}$ for the $i$-th firm. In particular, estimated parameters are used as weights, while variables are taken at individual level:

$$
Z_{h, i}^{e}=\hat{\alpha}_{1, h} S_{h, i}+\hat{\alpha}_{2, h} \pi_{h, i}
$$

where $Z_{h, i}^{e}$ is the covariate to be used in equation [3].

Following the ROC methodology, the export threshold firm $c$ is identified as the optimal cut-off . Finally, substituting the productivity and economic size of $c$ in Equation [6], we obtain the export threshold as:

$$
Z_{h, c}^{e}=\hat{\alpha}_{1, h} S_{h, c}+\hat{\alpha}_{2, h} \pi_{h, c}
$$

In the rest of the paper we refer to $Z_{h, c}^{e}$ as $Z^{e}$.

\subsection{Fitting tests of ROC estimates}

Three types of test are carried out. First, we apply the usual Area Under Curve (AUC) test to compare the model based on the composite indicator $Z$ with an alternative, strictly "Melitz-compliant" pure productivity model ( $\pi$-model), in which the export threshold is

\footnotetext{
${ }^{8}$ We refer to five geographical areas: North-West, North-East, Centre, South, Islands.
} 
defined over the labour productivity, measured in terms of value added per worker $(X=$ $\pi$ in Equation [3]).

Results are reported in Table 2: both $\pi$ - and $Z$-models show a high goodness of fit (never below $70 \%$ for the $\pi$-model, always over $75 \%$ for the $Z$-model). However, the $Z$-model significantly outperforms the pure productivity one for all industries.

Table 2. Area under ROC curve (AUC): comparison between $\pi$-model and $Z$-model

\begin{tabular}{|c|c|c|c|c|c|c|c|}
\hline \multirow[b]{2}{*}{ Industry } & \multicolumn{2}{|c|}{ AUCs } & \multicolumn{5}{|c|}{$Z$-model - $\pi$-model } \\
\hline & Z-model & $\pi$-model & $\begin{array}{c}\text { Difference } \\
\text { estimate }\end{array}$ & Standard error & Lower bound & Upper bound & P-value \\
\hline Food and beverage & 0.865 & 0.849 & 0.017 & 0.002 & 0.014 & 0.020 & 0.000 \\
\hline Textile & 0.824 & 0.767 & 0.058 & 0.004 & 0.050 & 0.065 & 0.000 \\
\hline Wearing apparel & 0.777 & 0.730 & 0.047 & 0.005 & 0.037 & 0.056 & 0.000 \\
\hline Leather & 0.756 & 0.698 & 0.058 & 0.005 & 0.048 & 0.067 & 0.000 \\
\hline Wood & 0.831 & 0.753 & 0.078 & 0.005 & 0.069 & 0.087 & 0.000 \\
\hline Paper and print & 0.843 & 0.785 & 0.058 & 0.003 & 0.051 & 0.064 & 0.000 \\
\hline Chemicals and pharmac & 0.787 & 0.741 & 0.046 & 0.008 & 0.030 & 0.063 & 0.000 \\
\hline Rubber and plastic & 0.818 & 0.742 & 0.076 & 0.005 & 0.066 & 0.085 & 0.000 \\
\hline Non metalic minerals & 0.769 & 0.732 & 0.037 & 0.004 & 0.030 & 0.044 & 0.000 \\
\hline Metals & 0.850 & 0.772 & 0.079 & 0.002 & 0.074 & 0.083 & 0.000 \\
\hline Electronics & 0.786 & 0.718 & 0.068 & 0.005 & 0.058 & 0.079 & 0.000 \\
\hline Machinery & 0.778 & 0.700 & 0.078 & 0.004 & 0.070 & 0.085 & 0.000 \\
\hline Automotive & 0.790 & 0.724 & 0.066 & 0.008 & 0.050 & 0.083 & 0.000 \\
\hline Furniture & 0.833 & 0.734 & 0.099 & 0.004 & 0.091 & 0.108 & 0.000 \\
\hline
\end{tabular}

Source: Authors' calculation on ISTAT data.

Second, we consider the capability of the cut-off identified by the $J$ index of classifying firms as exporters and non-exporters in terms of Precision and Accuracy. In particular, Precision measures the share of true positives over the total number of observations the model classifies as positives (i.e. the percentage of firms correctly classified as exporters):

$$
\text { Precision }=\frac{T P}{T P+F P}
$$

In turn, Accuracy measures the share of true positive and negative outcomes of the model (i.e. the proportion of firms correctly classified as exporters and non-exporters) over the total number of observations: 


$$
\text { Accuracy }=\frac{T P+T N}{\text { Total observations }}
$$

On such bases, we assess the capability of our model to detect the bulk of Italian exporters by calculating the weight of true positive observations in terms of total export.

The results of these latter tests are reported in Table 3. Our model shows a high capability of correctly clustering exporters: in 9 out of 14 industries, the Precision (column 2) is over $60 \%$ (over $80 \%$ in four industries). With regard to correct and wrong classifications (columns 3 to 5), the model shows a good performance in detecting true positives (i.e. in correctly classifying exporters), so discharging clustering errors on false negatives (i.e. firms that the model classifies as non-exporters despite they actually sell abroad some of their products). The last column confirms that our clustering method grasps an extremely large share of total export (over 97\% in all industries), suggesting that false negatives (which largely bear the bias of the model) are negligible or - accordingly to our definition of exporting firms - occasional exporters.

Table 3. Fitting tests of the ROC estimates

\begin{tabular}{|c|c|c|c|c|c|}
\hline Industry & Precision & $\begin{array}{l}\text { Accuracy (correct } \\
\text { clustering) }\end{array}$ & $\begin{array}{c}\text { Share of false } \\
\text { positives }\end{array}$ & $\begin{array}{c}\text { Share of false } \\
\text { negatives }\end{array}$ & $\begin{array}{l}\text { Share of export } \\
\text { for true positives }\end{array}$ \\
\hline Food and beverage & 49.1 & 80.5 & 15.8 & 3.7 & 99.5 \\
\hline Textile & 62.7 & 75.4 & 17.4 & 7.2 & 98.7 \\
\hline Wearing apparel & 59.3 & 71.7 & 19.3 & 9.0 & 97.5 \\
\hline Leather & 73.7 & 74.5 & 11.5 & 13.9 & 97.6 \\
\hline Wood & 34.0 & 76.0 & 21.3 & 2.8 & 97.9 \\
\hline Paper and print & 57.4 & 78.9 & 15.4 & 5.7 & 99.3 \\
\hline Chemicals and pharmaceutics & 84.3 & 71.0 & 11.2 & 17.8 & 99.3 \\
\hline Rubber and plastic & 84.2 & 73.9 & 9.1 & 17.0 & 97.9 \\
\hline Non metalic minerals & 54.8 & 74.0 & 18.1 & 7.9 & 98.4 \\
\hline Metals & 59.4 & 80.0 & 14.1 & 5.9 & 98.7 \\
\hline Electronics & 83.8 & 72.2 & 8.7 & 19.0 & 97.3 \\
\hline Machinery & 85.5 & 69.3 & 9.1 & 21.6 & 96.6 \\
\hline Automotive & 74.0 & 71.3 & 15.3 & 13.5 & 99.3 \\
\hline Furniture & 67.9 & 79.9 & 11.9 & 8.2 & 97.5 \\
\hline
\end{tabular}

Source: Authors' calculation on Istat data

Third, another way of looking at how the $Z$-model outperforms the pure productivity model concerns the distribution of exporting and non-exporting firms according to their values of productivity and $Z$. As Figure 2 clearly shows, once we take into account the $Z$ indicator - i.e. once we move from considering just productivity, as in Melitz (2003) to 
considering a combination of productivity and economic size - in all industries the distributions overlap substantially shrinks to a very limited area.

Figure 2. Labour productivity (left) and $Z$ indicator (right) for firms over and under the export threshold ${ }^{9}$
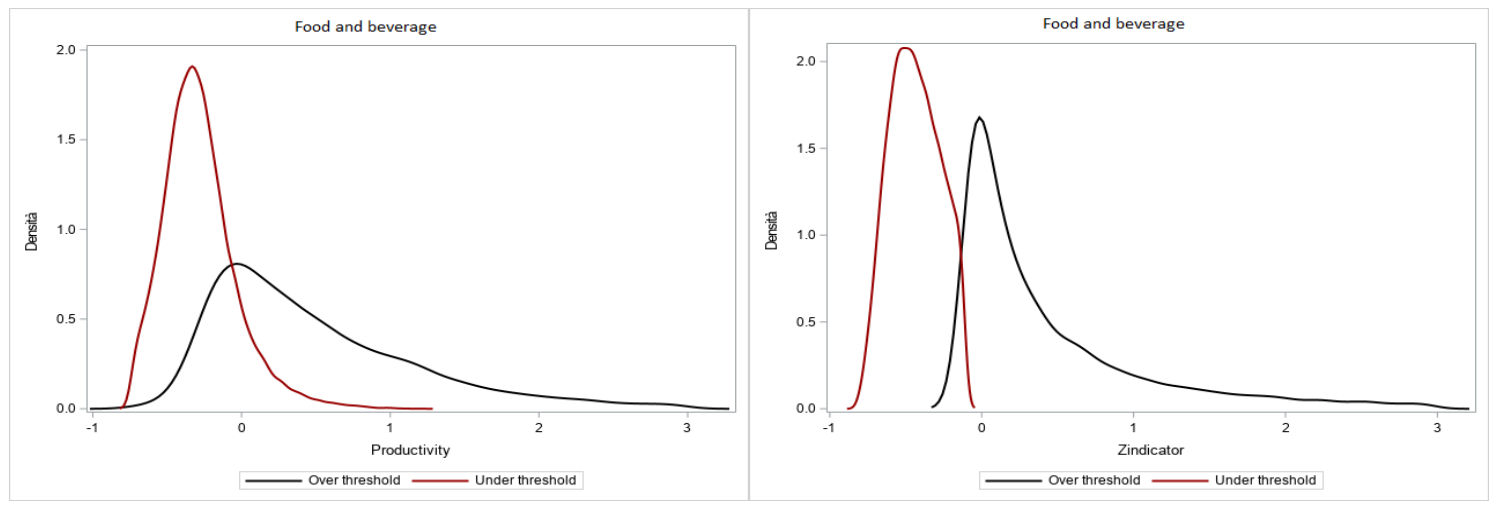

Source: Authors' calculations on Istat data

\section{The Technology line}

In this section, we use productivity and economic size to estimate firms' positioning within the industry in terms of technological intensity. The minimum combination between these two variables necessary to become an exporter might not be consistent with the adoption of an advanced technology. As mentioned in Section 1, the literature has shown that an exporting firm can display the same (low) level of technology of a nonexporting firm (Bustos, 2011; Bertschek et al., 2016). It follows that technology may be a not-crucial element in determining the exporting status of a firm, and a mismatch between the conditions required to export and those ensuring a high level of technology may emerge.

In order to shed further light on such mismatch, we set up a two-step procedure. First, we estimate the relative weights of economic size and productivity corresponding to a 'high' level of technology, here defined as a higher-than-average level within the industry. Second, to assess the technological level of firms laying over and under the export threshold, we define a 'technology line', which is the locus of all the combinations of economic size and productivity which would guarantee to the export threshold firm (i.e.

\footnotetext{
${ }^{9} \mathrm{We}$ included in the text only Food and beverage. Figures for all industries in Appendix A.
} 
the first exporter) a higher-than-average level of technology. This way, the possibility of measuring each firm's distance from the export threshold and the technology line provides new insights on the possible mismatch between the technological levels of exporters and non-exporters, and has some important consequences for policy-making purposes.

In the first step, we build a firm-level proxy of technology using the same measure of technology as in Bustos (2011), which includes spending on computers and software, payments for technology transfers and patents, spending on R\&D. ${ }^{10}$ Successively, for each industry, a logit model of the probability for a firm to have a technology level higher than the industry average value is estimated, using the same covariates and controls as in Equation [5]:

$$
\operatorname{Prob}\left(\text { Tech. level }_{i}>\operatorname{Avg} \mid S_{i}, \pi_{i}, G_{i}, I_{i}\right)=\Lambda\left(\alpha_{1} S_{i}+\alpha_{2} \pi_{i}+\alpha_{3} G_{i}+\alpha_{4} I_{i}\right)
$$

From this estimate, we use the relative weights of economic size $(S)$ and productivity $(\pi)$ to calculate, for each firm in the $h$-th industry, the following composite indicator:

$$
Z_{h, i}^{t}=\hat{\alpha}_{1, h} S_{h, i}+\hat{\alpha}_{2, h} \pi_{h, i}
$$

In the second step, among the bundle of parallel lines represented by Equation [11], we identify the technology line in a plane with $x$ axis $=S$ and $y$ axis $=\pi$ as the line passing through the values of economic size and productivity of the export threshold firm $c\left(S_{h, c}\right.$ and $\pi_{h, c}$, respectively):

$$
Z_{h, c}^{t}=\hat{\alpha}_{1, h} S_{h, c}+\hat{\alpha}_{2, h} \pi_{h, c}
$$

where $Z_{h, c}^{t}$ (hereinafter: $Z^{t}$ ) is the technology line.

\footnotetext{
10 This information is obtained from administrative sources and included in the aforementioned business register "Frame-Sbs". We summarize them through a factor analysis in a synthetic indicator. Then we build a binary variable to be used as a dependent variable in Equation [10], which takes value 1 when firm expenditure on technology is higher than industry average, 0 otherwise.
} 


\section{Mapping the business system: a new taxonomy of firms}

On the basis of the positioning of firms with respect to $Z^{e}$ and $Z^{t}$ it is possible to derive a four-class taxonomy which qualifies the comparison between exporting and non-exporting firms in the light of their technological level within the industry. In fact, the space defined by the interaction of $Z^{e}$ and $Z^{t}$ ideally defines four areas as depicted in Figure 3:

Figure 3. The taxonomy of firms export orientation

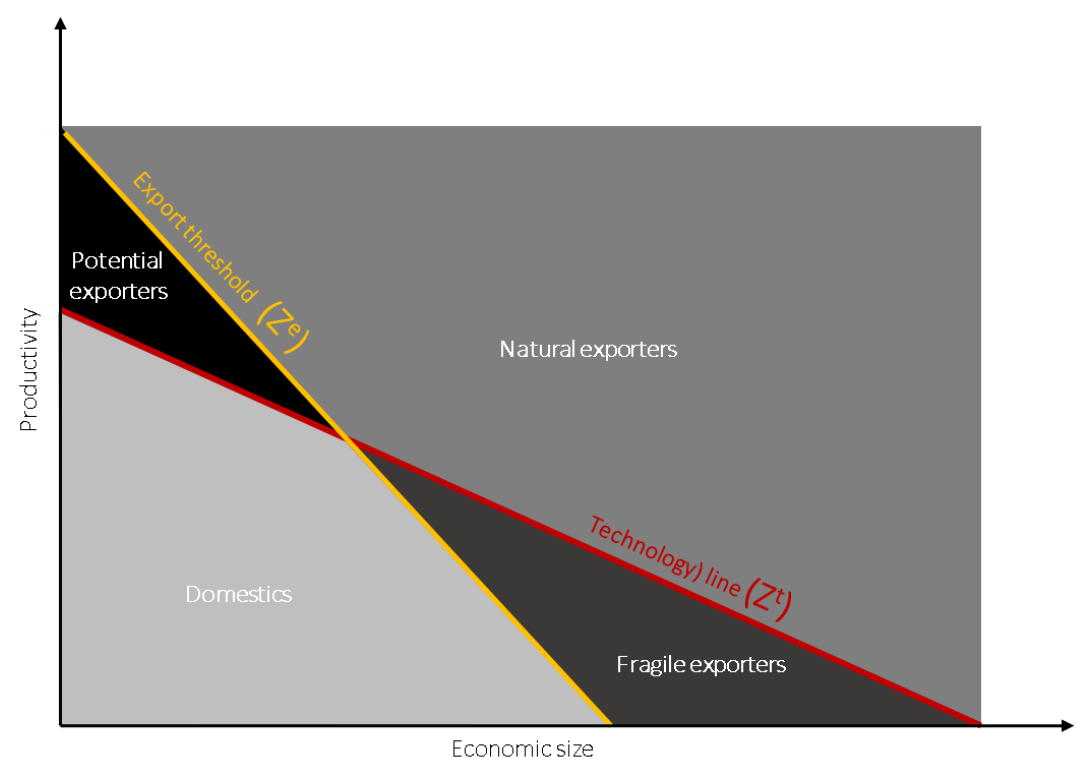

- Natural exporters: firms with $Z_{i}^{e}>Z^{e}$ and $Z_{i}^{t}>Z^{t}$, i.e. high-tech firms that are productive and/or large enough to export.

- Fragile exporters: firms with $Z_{i}^{e}>Z^{e}$ and $Z_{i}^{t}<Z^{t}$, i.e. low-tech firms that are productive and/or large enough to export.

- Potential exporters: firms with $Z_{i}^{e}<Z^{e}$ and $Z_{i}^{t}>Z^{t}$, i.e. high-tech firms that are neither productive or/nor large enough to export.

- Domestics: firms with $Z_{i}^{e}<Z^{e}$ and $Z_{i}^{t}<Z^{t}$, i.e. low-tech firms that are neither productive or/nor large enough to export. 
Fragile and Potential exporters are the two classes where a mismatch between export activity and technology levels $\left(Z^{e}\right.$ and $\left.Z^{t}\right)$ emerges.

Figure 4 plots the distribution of firms in the four classes according to their respective distance from the values of $Z^{e}$ and $Z^{t}$ (where these latter ones are indicated as axes in the graphs) and reports the relative weights of each class. The heterogeneity among exporters (Fragile and Naturals) and non-exporters (Domestics and Potentials) is noticeable. Moreover, in all industries, the class of Domestics tends to outnumber the others, with the exceptions of Machinery and Chemical and pharmaceutics, i.e. the industries with the highest percentages of exporting firms and especially of Natural exporters (but this latter type of firms are also common in Textile and Rubber and plastic).

Figure 4. Mapping business system: interaction between export threshold and technology line
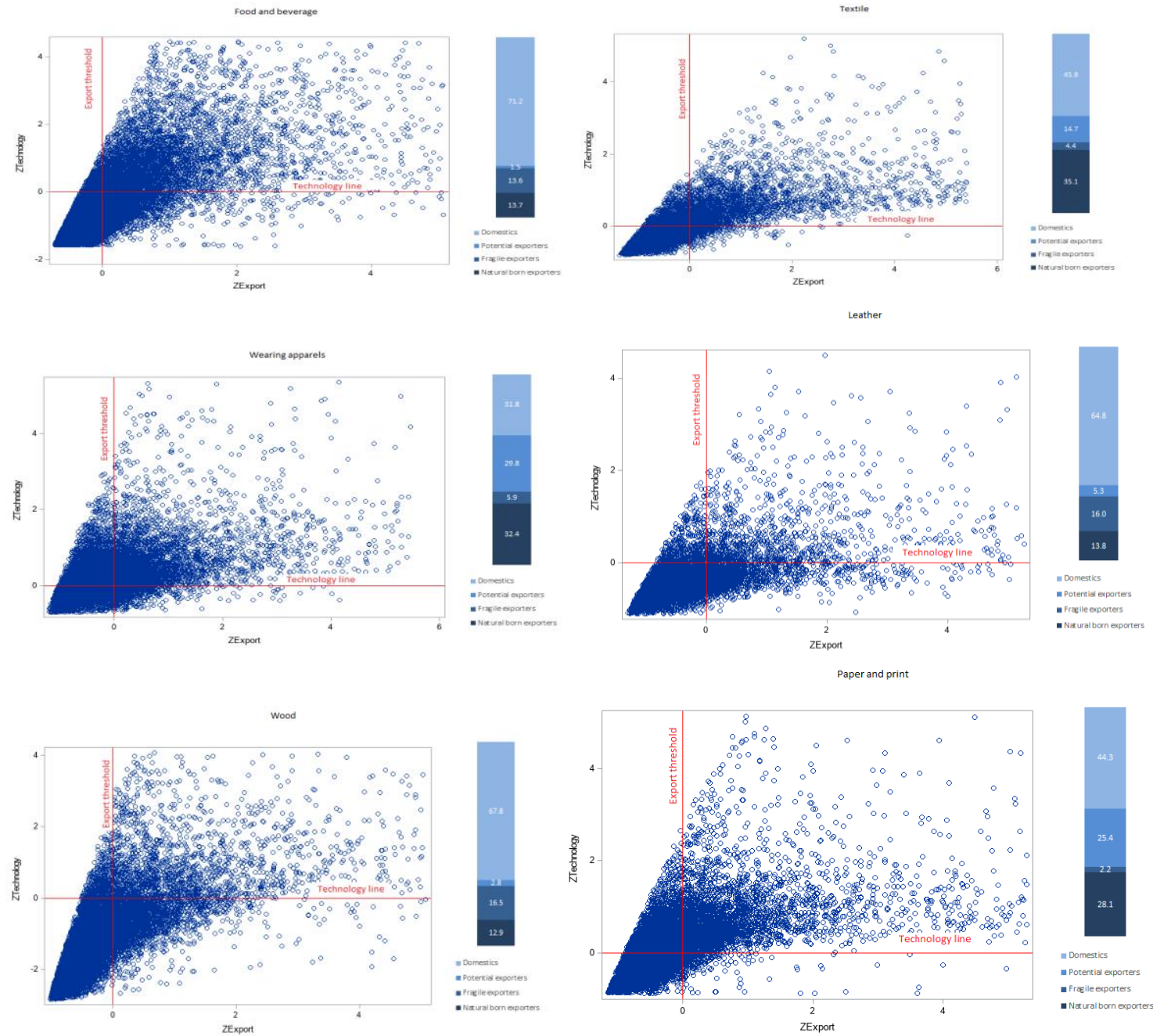

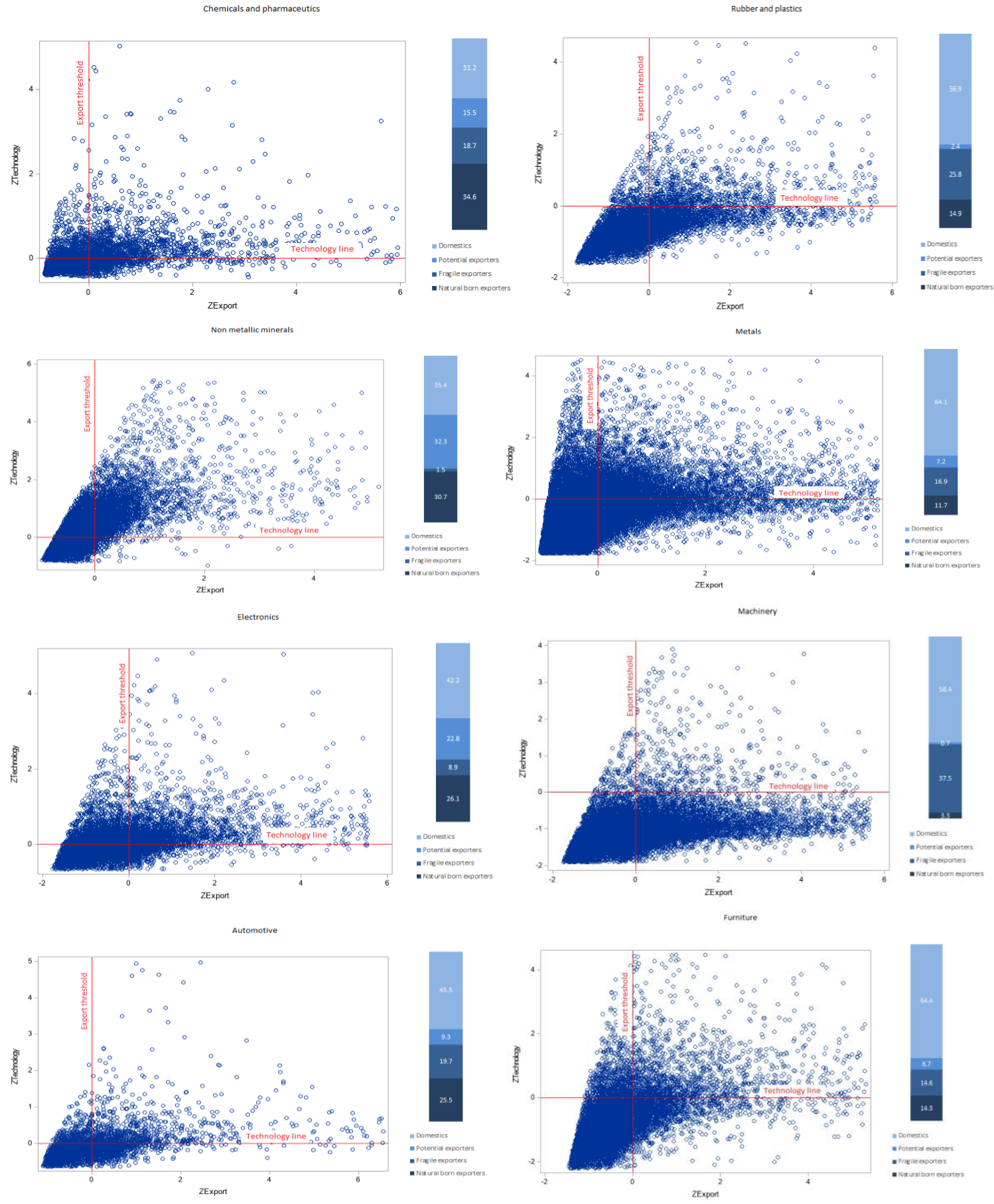

Source: Authors' calculation on Istat data.

Moving from this taxonomy, Table 4 reports some descriptive evidence about these different classes by industry. Italian manufacturing comes out as a polarized system: in almost every industry, while Domestics account for the majority of firms, Natural exporters largely dominate in terms of share of value added and turnover. 
Table 4. Characteristics of firms by typology and industry

\begin{tabular}{|c|c|c|c|c|c|c|c|c|}
\hline Industry & Taxonomy & $\begin{array}{c}\text { Firms } \\
\text { (shares of total } \\
\text { industry) }\end{array}$ & $\begin{array}{l}\text { Value added } \\
\text { (Shares of total } \\
\text { industry) }\end{array}$ & $\begin{array}{l}\text { Turnover } \\
\text { (Shares of total } \\
\text { industry) }\end{array}$ & $\begin{array}{l}\text { Employment } \\
\text { (Mean, Workers) }\end{array}$ & $\begin{array}{l}\text { Labor productivity } \\
\text { (Mean, thousand } \\
\text { euro) }\end{array}$ & $\begin{array}{c}\text { Export/turnover } \\
\text { ratio (Mean \%) }\end{array}$ & $\begin{array}{l}\text { Shares of firms } \\
\text { belonging to MNE }\end{array}$ \\
\hline \multirow{4}{*}{$\begin{array}{l}\text { Food and } \\
\text { beverage }\end{array}$} & Domestics & 71.2 & 8.8 & 5.2 & 4.0 & 19.7 & & 0.8 \\
\hline & Potential Exporters & 1.5 & 0.4 & 0.2 & 3.0 & 52.2 & & 1.4 \\
\hline & Fragile Exporters & 13.6 & 19.2 & 18.2 & 21.2 & 42.7 & 11.1 & 6.0 \\
\hline & Natural exporters & 13.7 & 71.7 & 76.3 & 32.5 & 103.4 & 19.4 & 13.8 \\
\hline \multirow{4}{*}{ Textile } & Domestics & 45.8 & 5.0 & 4.0 & 4.0 & 18.9 & & 1.0 \\
\hline & Potential Exporters & 14.7 & 3.5 & 2.8 & 4.3 & 39.3 & & 0.9 \\
\hline & Fragile Exporters & 4.4 & 1.8 & 1.7 & 13.5 & 21.3 & 18.9 & 7.5 \\
\hline & Natural exporters & 35.1 & 89.7 & 91.5 & 27.8 & 64.4 & 28.5 & 11.9 \\
\hline \multirow{4}{*}{ Wearing apparel } & Domestics & 31.8 & 3.4 & 2.8 & 4.7 & 13.1 & & 0.2 \\
\hline & Potential Exporters & 29.8 & 7.0 & 5.8 & 4.6 & 29.6 & & 0.4 \\
\hline & Fragile Exporters & 5.9 & 2.0 & 2.1 & 14.8 & 13.6 & 25.7 & 5.2 \\
\hline & Natural exporters & 32.4 & 87.5 & 89.3 & 26.8 & 58.7 & 32.9 & 8.9 \\
\hline \multirow{4}{*}{ Leather } & Domestics & 64.8 & 11.3 & 7.7 & 5.9 & 23.5 & & 1.0 \\
\hline & Potential Exporters & 5.3 & 1.5 & 1.2 & 3.8 & 57.0 & & 1.3 \\
\hline & Fragile Exporters & 16.0 & 20.7 & 19.3 & 30.5 & 33.9 & 38.2 & 7.8 \\
\hline & Natural exporters & 13.8 & 66.6 & 71.8 & 39.7 & 97.0 & 43.2 & 16.1 \\
\hline \multirow{4}{*}{ Wood } & Domestics & 67.8 & 14.4 & 11.8 & 2.4 & 20.7 & & 1.3 \\
\hline & Potential Exporters & 2.8 & 1.1 & 0.8 & 1.7 & 50.7 & & 0.2 \\
\hline & Fragile Exporters & 16.5 & 21.4 & 19.7 & 9.9 & 30.2 & 14.8 & 4.9 \\
\hline & Natural exporters & 12.9 & 63.1 & 67.6 & 18.0 & 62.3 & 17.3 & 8.0 \\
\hline \multirow{4}{*}{ Paper and print } & Domestics & 44.3 & 3.6 & 3.0 & 3.1 & 18.8 & & 1.4 \\
\hline & Potential Exporters & 25.4 & 5.8 & 4.6 & 4.1 & 39.2 & & 1.4 \\
\hline & Fragile Exporters & 2.2 & 4.5 & 6.0 & 31.4 & 45.0 & 6.8 & 10.3 \\
\hline & Natural exporters & 28.1 & 86.0 & 86.3 & 29.1 & 74.0 & 11.3 & 10.7 \\
\hline \multirow{4}{*}{$\begin{array}{l}\text { Chemicals and } \\
\text { pharmaceutics }\end{array}$} & Domestics & 31.2 & 1.0 & 1.1 & 5.5 & 33.2 & & 2.6 \\
\hline & Potential Exporters & 15.5 & 1.7 & 1.7 & 7.6 & 80.3 & & 10.0 \\
\hline & Fragile Exporters & 18.7 & 42.6 & 45.8 & 112.1 & 110.8 & 25.3 & 27.3 \\
\hline & Natural exporters & 34.6 & 54.6 & 51.4 & 58.7 & 146.4 & 31.1 & 43.2 \\
\hline \multirow{4}{*}{$\begin{array}{l}\text { Rubber and } \\
\text { plastic }\end{array}$} & Domestics & 56.9 & 8.8 & 7.7 & 6.2 & 37.9 & & 2.5 \\
\hline & Potential Exporters & 2.4 & 0.5 & 0.5 & 3.9 & 88.6 & & 2.7 \\
\hline & Fragile Exporters & 25.8 & 26.3 & 25.3 & 30.0 & 51.2 & 21.7 & 15.5 \\
\hline & Natural exporters & 14.9 & 64.3 & 66.5 & 70.2 & 93.1 & 32.0 & 31.8 \\
\hline \multirow{4}{*}{$\begin{array}{l}\text { Non metalic } \\
\text { minerals }\end{array}$} & Domestics & 35.4 & 2.0 & 2.0 & 3.1 & 14.3 & & 1.5 \\
\hline & Potential Exporters & 32.3 & 6.3 & 5.6 & 4.5 & 33.2 & & 1.1 \\
\hline & Fragile Exporters & 1.5 & 17.8 & 19.2 & 123.9 & 71.2 & 27.8 & 23.6 \\
\hline & Natural exporters & 30.7 & 73.8 & 73.2 & 24.9 & 73.9 & 24.7 & 12.4 \\
\hline \multirow{4}{*}{ Metals } & Domestics & 64.1 & 12.2 & 8.6 & 4.4 & 32.3 & & 1.3 \\
\hline & Potential Exporters & 7.2 & 3.3 & 2.1 & 4.5 & 74.8 & & 2.3 \\
\hline & Fragile Exporters & 16.9 & 24.8 & 23.3 & 26.0 & 41.9 & 19.4 & 10.1 \\
\hline & Natural exporters & 11.7 & 59.8 & 66.0 & 42.6 & 89.0 & 27.4 & 17.3 \\
\hline \multirow{4}{*}{ Electronics } & Domestics & 42.2 & 4.1 & 3.3 & 5.9 & 29.4 & & 1.9 \\
\hline & Potential Exporters & 22.8 & 5.4 & 4.4 & 7.0 & 60.4 & & 6.8 \\
\hline & Fragile Exporters & 8.9 & 4.1 & 4.8 & 26.8 & 30.7 & 25.6 & 14.2 \\
\hline & Natural exporters & 26.1 & 86.4 & 87.5 & 71.4 & 82.5 & 36.1 & 32.1 \\
\hline \multirow{4}{*}{ Machinery } & Domestics & 58.4 & 9.9 & 8.8 & 6.7 & 47.2 & & 3.4 \\
\hline & Potential Exporters & 0.7 & 0.2 & 0.2 & 2.6 & 163.4 & & 1.5 \\
\hline & Fragile Exporters & 37.5 & 63.6 & 63.1 & 44.8 & 70.1 & 41.1 & 24.0 \\
\hline & Natural exporters & 3.3 & 26.3 & 27.9 & 112.3 & 129.5 & 51.3 & 40.2 \\
\hline \multirow{4}{*}{ Automotive } & Domestics & 45.5 & 2.0 & 1.1 & 8.2 & 31.8 & & 1.7 \\
\hline & Potential Exporters & 9.3 & 0.9 & 0.6 & 9.2 & 66.2 & & 7.3 \\
\hline & Fragile Exporters & 19.7 & 4.4 & 3.2 & 37.7 & 35.7 & 27.1 & 14.7 \\
\hline & Natural exporters & 25.5 & 92.7 & 95.0 & 254.9 & 86.4 & 39.5 & 37.2 \\
\hline \multirow{4}{*}{ Furniture } & Domestics & 64.4 & 11.0 & 8.5 & 3.6 & 23.9 & & 1.5 \\
\hline & Potential Exporters & 6.7 & 2.4 & 1.9 & 3.4 & 53.0 & & 2.0 \\
\hline & Fragile Exporters & 14.6 & 18.4 & 18.3 & 19.5 & 32.5 & 24.6 & 7.9 \\
\hline & Natural exporters & 14.3 & 68.2 & 71.3 & 34.4 & 69.2 & 32.9 & 12.1 \\
\hline
\end{tabular}

Source: Authors' calculation on Istat data.

From analytical and policy-making points of view, however, the most interesting groups are Fragile and Potential exporters. The formers are numerous especially in Machinery (where they account for over one third of the total), Rubber and plastics, Automotive, and Chemicals and pharmaceutics. This might be related to factors such as the participation in GVC and/or intra-group trade. In this respect, the last column of Table 4 reports, for each class, the share of firms belonging to a multinational group. However, the incidence among Fragile exporters is generally low, ranging from $4.9 \%$ in Wood and $27.3 \%$ in 
Chemicals and pharmaceutics. This implies that this class of the taxonomy is only partially affected by such aspect.

As for Potential exporters, they are relatively common (with shares ranging from 22.8 to over $32 \%$ ) in Non-metallic minerals, Wearing apparels, Electronics, Paper and print. This class represents what policy measures aiming at increasing the number of exporting firms (i.e. to stimulate domestic units to cross the export threshold) need to focus on, considering their peculiarities and heterogeneity. In this vein, an important size-related aspect emerges, due to all Potential exporters, in all industries, being small-sized enterprises, counting less than 50 workers. In other terms, this class of the taxonomy includes generally small (possibly undersized) firms which nonetheless have a significant economic size - possibly due to relatively high levels of turnover and/or capital intensity, or because they are characterized by a long-lasting activity - and show technology levels comparable to those of Natural exporters. ${ }^{11}$

Even more interestingly, in virtually each industry, Potential exporters are substantially smaller and more productive than Fragile exporters. On the one hand, this suggests that on average, in order to have the Potential exporters cross the export threshold, a recovery in size appears more suitable than an increase in productivity. On the other hand, in order for Fragile exporters to become Natural exporters, an increase in productivity appears to be more relevant than a recovery in size.

However, the extent to which Potential exporters (Fragile exporters) may reach the export threshold (technology line) by recovering size (productivity) also depends on the initial positioning of firms with respect to the export threshold (technology line) itself. In this context, our approach allows for measuring the distance of each firm from both: the median value of the distance for the four classes is displayed in Figure 5. In all industries, with the exception of Food and beverage and Wood where the share of exporters is lower, the distribution of firms across the export threshold (red markers) appears to be more dispersed with respect to the one referring to the technology line (black markers). In other

\footnotetext{
${ }^{11}$ There are a number of possible reasons for this. For example, in terms of the model by Lileeva and Trefler (2010), such firms may be domestic units which have invested in technology and are expected to be shifting to exporter status (in our terms: crossing the export threshold). Moreover, they may also be units belonging to enterprises groups in which specific branches are in charge of the export activity for the entire group. Furthermore, our Potential exporters may include suppliers of other exporting firms; in this case a possible high-technology, exporting buyer could stimulate its intermediate goods suppliers to adopt an advanced technology, so that the (generally small-sized) suppliers would end up crossing the technology line without reaching the export threshold.
} 
terms, the path of technology adoption appears to be more concentrated than the capability to export, confirming the fact that the exporter status does not necessarily entail high level of technology, as pointed out by Bustos (2011).

Figure 5. Distance from the export threshold and technology line by industry and taxonomy (median values)

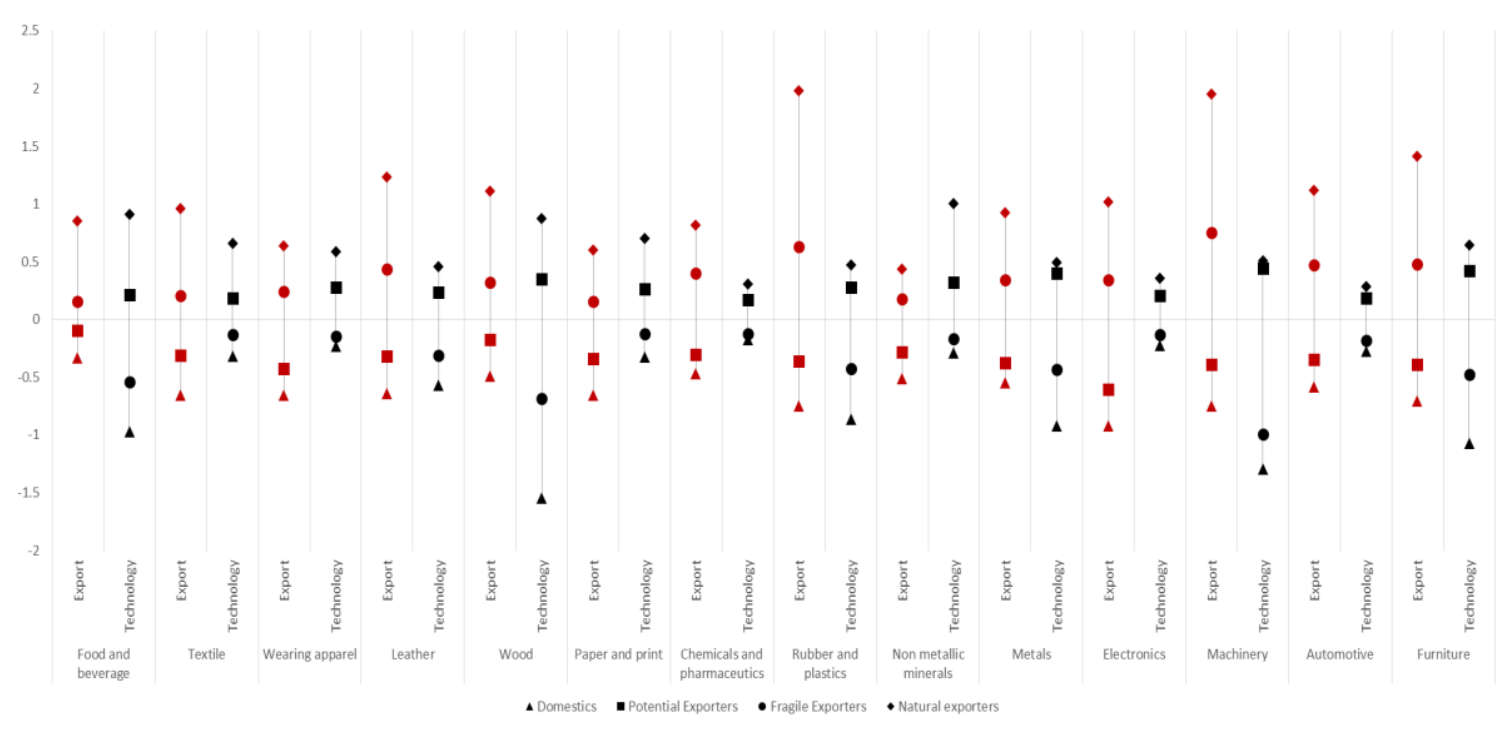

Source: Authors' calculation on Istat data.

\section{Conclusions}

In this paper, we analyse the potential mismatch between the conditions required for a firm to become an exporter and the pattern of technology adoption in its industry. In particular, we provide a methodology that allows to cluster business units according to their export orientation and technology in order to distinguish what firms are able to export despite their relatively low technology, and, more importantly, which firms do not export notwithstanding their relatively high level of technology.

To do so, we firstly use our ROC-based methodology to estimate, for each industry, the export threshold, defined as the firm-level minimum combination of productivity and economic size corresponding to the transition from the non-exporter to exporter status. Successively, we introduce the technology line, i.e. the level of technology the export threshold firm would have if its combination of productivity and economic size would correspond to a higher-than-average technology in the industry. The presence of a 
compensation between productivity and economic size in exporting, in fact, may imply the possibility of a mismatch between export- and technology- related combinations.

The interaction between the export threshold and the technology line allows us to derive a taxonomy that classifies firms in terms of the conditions needed to export and to adopt a high level of technology. This classification is especially important from a policy-making point of view, because it allows for a new breakdown of exporters and non-exporters. In this model, Fragile exporters are low-tech exporting firms, while Potential exporters are high-tech non exporting firms. The formers are comparable with the particular set of exporting firms that have not yet adopted the higher technology, as pointed out in existing literature. The latter are a new class of firms identified by our approach. This division allows to highlight the existence of a specific group of non-exporting enterprises which are more likely to become exporters. This portion of the manufacturing sector would be the ideal target for policy measures aimed at increasing the participation of firms in international markets. The possibility of singling it out within the universe of nonexporting firms allows to design more precise policies, thus increasing their effectiveness and, eventually, reducing their costs to Governments. 


\section{REFERENCES}

Berge, Travis J., and Òscar Jordà. 2011. "Evaluating the Classification of Economic Activity into Recessions and Expansions." American Economic Journal: Macroeconomics 3 (2): 246-277.

Bernard, Andrew B., Jonathan Eaton, J. Bradford Jensen, and Samuel Kortum. 2003. "Plants and Productivity in International Trade." American Economic Review 93 (4): $1268-1290$.

Bernard, Andrew B., Stephen J. Redding, and Peter K. Schott. 2011. "Multi-product Firms and Trade Liberalization." Quarterly Journal of Economics 126 (3): 12711318. https ://doi.org/10.1093/qje/qjr02.

Bertschek, Irene, Jan Hogrefe, and Fabienne Rasel. 2016. "Trade and Technology: New Evidence on the Productivity Sorting of Firms." Review of World Economics 151 (1): 53-72.

Bustos, Paula. 2011. "Trade Liberalization, Exports, and Technology Upgrading: Evidence on the Impact of MERCOSUR on Argentinian Firms." American Economic Review 101 (1): 304-340.

Castellani, Davide, and Antonello Zanfei. 2007. "Internationalisation, Innovation and Productivity: How Do Firms Differ in Italy.” World Economy 30 (1): 156-176.

Chaney, Thomas. 2008. "Distorted Gravity: The Intensive and Extensive Margins of International Trade." American Economic Review 98 (4): 1707-1721. https://doi.org/10.1257/aer.98.4.1707

Costa, Stefano, Federico Sallusti, Claudio Vicarelli, and Davide Zurlo. 2019. "Over the ROC Methodology: Productivity, Economic Size and Firms' Export Thresholds." Review of International Economics 27 (3): 955-980. doi: 10.1111/roie.12405.

Delgado, Miguel A., Jose C. Fariñas and Sonia Ruano. 2002. "Firm Productivity and Export Markets: A Non-parametric Approach.” Journal of International Economic 57 (2): 397-422.

Fawcett, Tom. 2005. “An Introduction to ROC Analysis." Pattern Recognition Letters 27: 861-874. doi:10.1016/j.patrec.2005.10.010.

Geishecker, Ingo, Philipp J.H. Schröder, and Allan Sørensen. 2017. "Explaining the Size Differences of Exporter Premia: Theory and Evidence." Review of World Economics, 153 (2): 327-351.

ISGEP - International Study Group on Exports and Productivity. 2008. "Understanding Cross-Country Differences In Export Premia: Comparable Evidence for 14 Countries." Review of World Economics 144 (4): 596-635.

Khandani, Amir E., J. Kim Adlar, and W. Lo. Andrew. 2010. "Consumer Credit-Risk Models via Machine-Learning Algorithms." Journal of Banking and Finance, 34 (11): 2767-2787. 
Kumar, Rajeev, and Abhaya Indrayan. 2011. "Receiver operating characteristic (ROC) curve for medical researchers." Indian Pediatrics, 48 (4): 277-287. https://doi.org/10.1007/s13312-011-0055-4.

Leung, Danny, Cesaire Meh, and Yaz Terajima. 2008. "Productivity in Canada: Does Firm Size Matter?.” Bank of Canada Review, Autumn: 7-16.

Lileeva, Alla, and Daniel Trefler. 2010. "Improved Access to Foreign Markets Raises Plant-level Productivity For Some Plants." Quarterly Journal of Economics 125 (3): 1051-1099.

Lusted, Lee B. 1960. "Logical Analysis in Roentgen Diagnosis: Memorial Fund Lecture." Radiology 74 (2): 178-93.

Majnik, Matjaz, and Zoran Bosnić. 2013. "ROC Analysis of Classifiers in Machine Learning: A Survey." Intelligent Data Analysis 17: 531-558. doi: 10.3233/IDA130592.

Majocchi, Antonio, Emanuele Bacchiocchi, and Ulrike Mayrhofer. 2005. "Firm Size, Business Experience and Export Intensity in SMEs: A Longitudinal Approach To Complex Relationships." International Business Review, 14: 719-738.

Máñez-Castillejo, Juan A., Maria. E. Rochina-Barrachina, and Juan A. SanchisLlopis. 2010. "Does Firm Size Affect Self-selection and Learning-by-exporting?." The World Economy 33 (3): 315-346.

Melitz, Marc J. 2003. "The Impact of Trade on Intra-industry Reallocations and Aggregate Industry Productivity." Econometrica 71: 1695-1725. doi: 10.1111/14680262.00467.

Melitz, Marc. J., and Gianmarco I.P. Ottaviano. 2008. "Market Size, Trade and Productivity." Review of Economic Studies 75: 295-316. doi.org/10.1111/j.1467937X.2007.00463.x.

Pepe, Margaret S. 2003. The Statistical Evaluation of Medical Tests for Classification and Prediction. Oxford, UK: Oxford University Press.

Schröder, Phillipp J.H., and Allan Sørensen. 2012. "Second Thoughts on the Exporter Productivity Premium." Canadian Journal of Economics 45 (4): 1310-1331. https://doi.org/10.1111/j.1540-5982.2012.01742.x

Syverson, Chad. 2011. "What Determines Productivity?." Journal of Economic Literature 49 (2): 326-365. https://doi.org/10.1257/jel.49.2.326.

Tybout, James R. 2000. "Manufacturing Firms in Developing Countries: How Well Do They Do and Why?." Journal of Economic Literature 38 (1): 11-44. https://doi.org/10.1257/jel.38.1.11.

Wagner, Joachim. 1995. "Exports, Firm Size, and Firm Dynamics." Small Business Economics 7: 29- 39.

Wagner, Joachim. 2007. "Exports and Productivity: A Survey of the Evidence From Firm Level Data." The World Economy 30 (1): 60-82. https ://doi.org/10.1111/j.14679701.2007.00872.x. 
Wagner, Joachim. 2012. "International Trade and Firm Performance: A Survey of Empirical Studies Since 2006." Review of World Economics 148 (2): 235-267. https://doi.org/10.1007/s10290-011-0116-8.

Warnock, David G., and Carl Peck. 2010. “A Roadmap for Biomarker Qualification.” Nature Biotechnology 28: 444-445. doi: 10.1038/nbt0510-444.

Youden, William. J. 1950. "Index for Rating Diagnostic Tests." Cancer 3: 32-35. doi: 10.1002/1097-0142(1950)3:1<32::AID-CNCR2820030106>3.0.CO;2-3. 
Appendix A. Distribution of labour productivity (Left) and $Z$ indicator (Right) for firms over and under the export threshold (Kernel density)
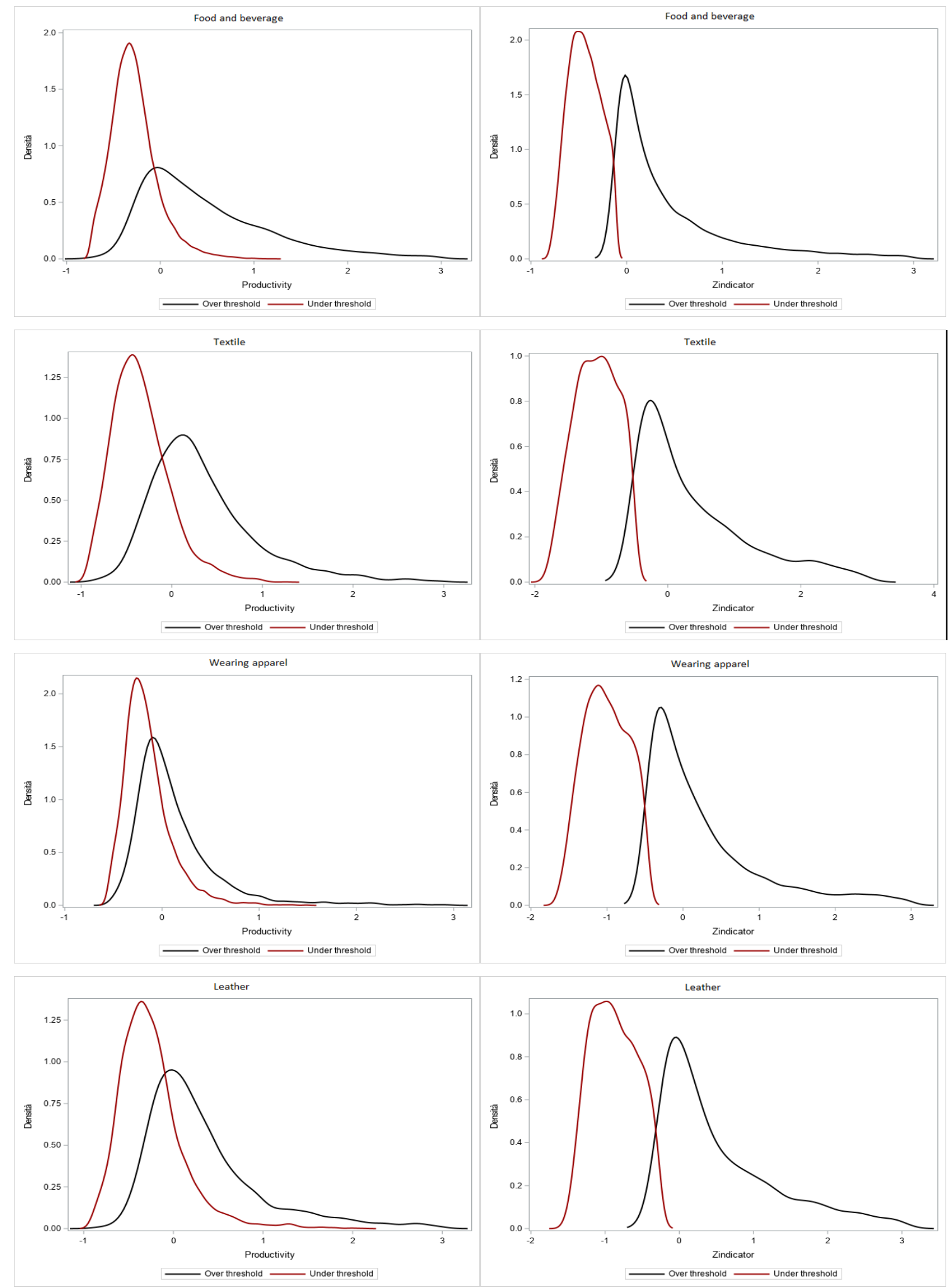

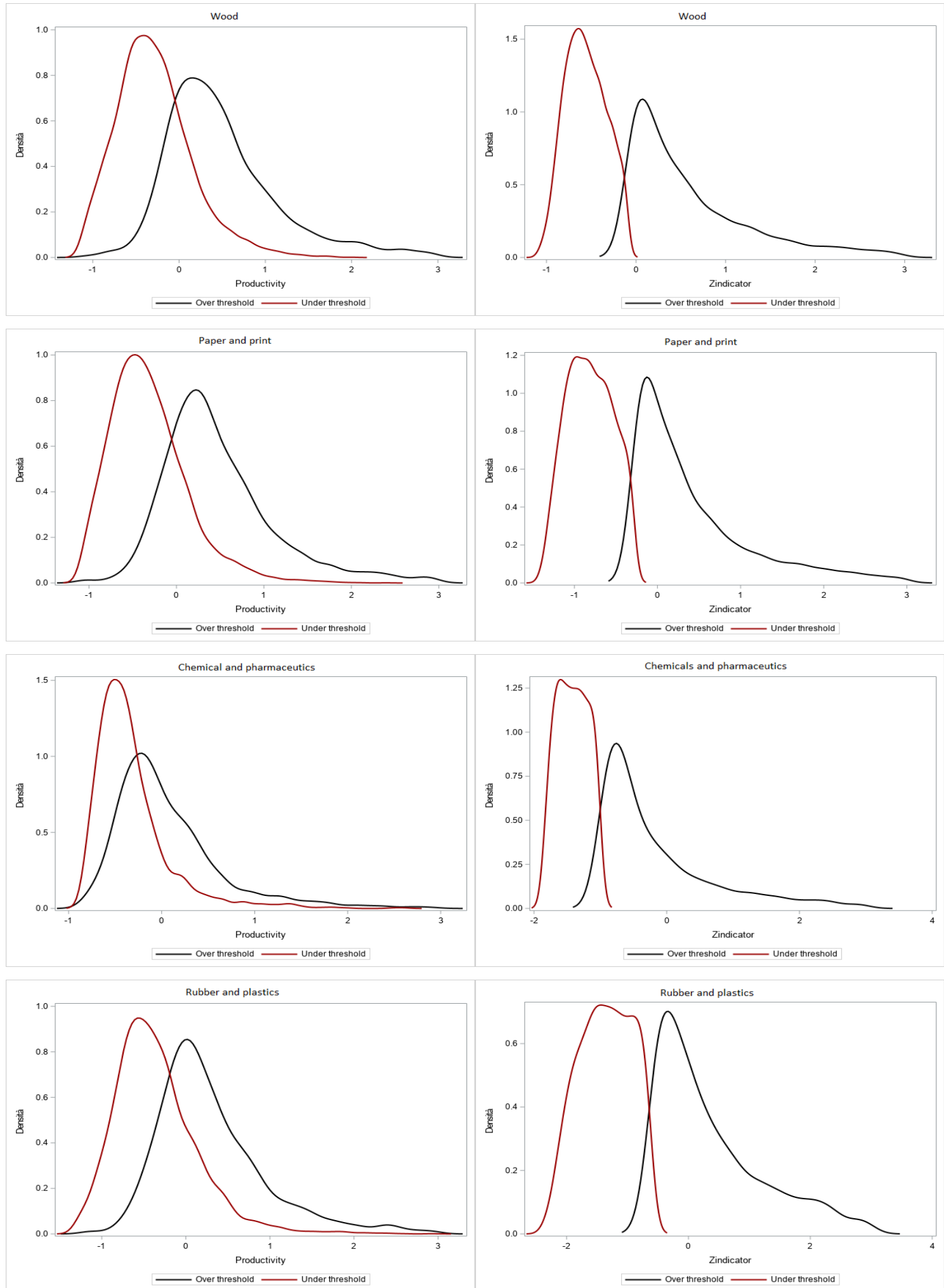

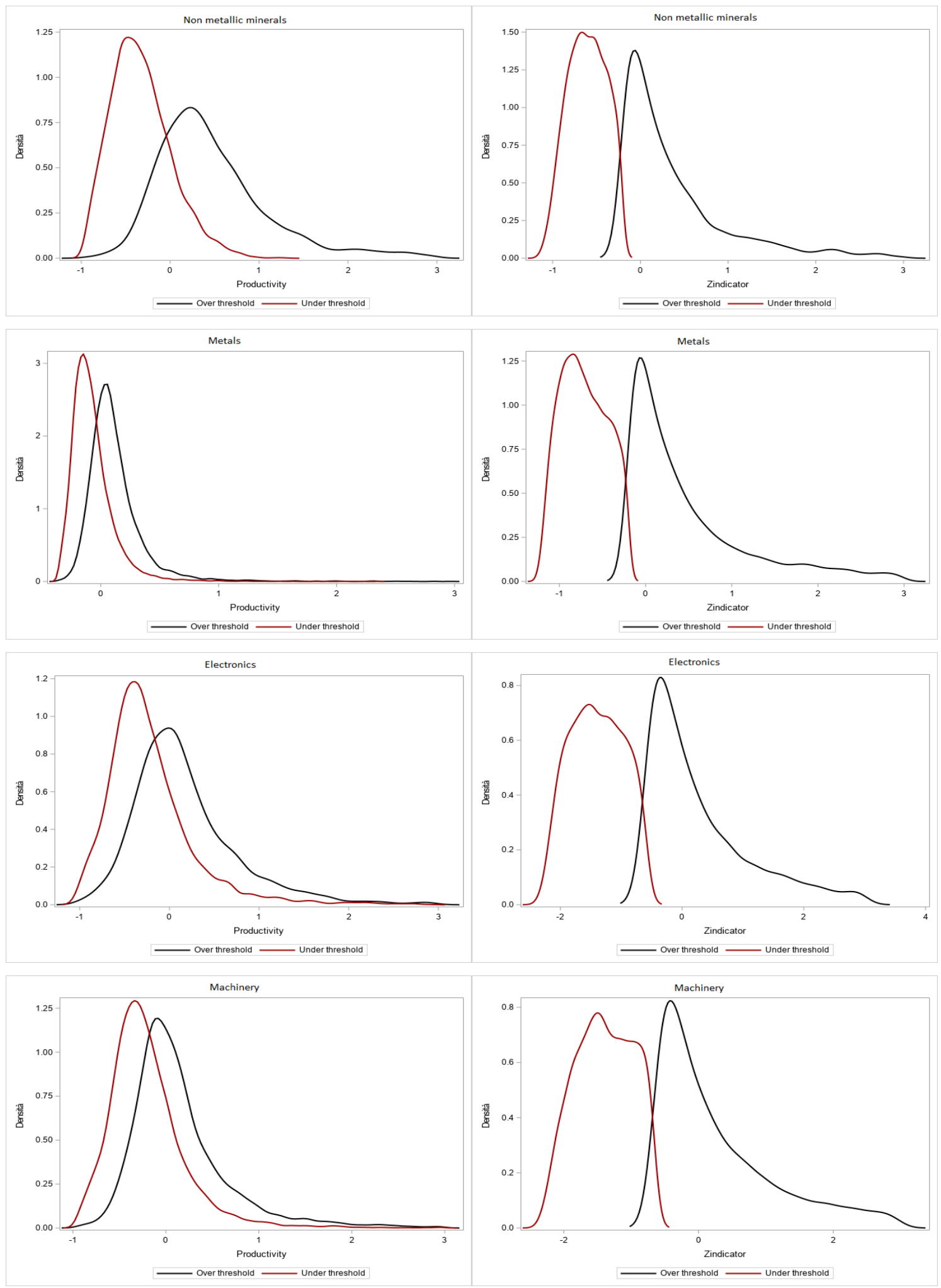

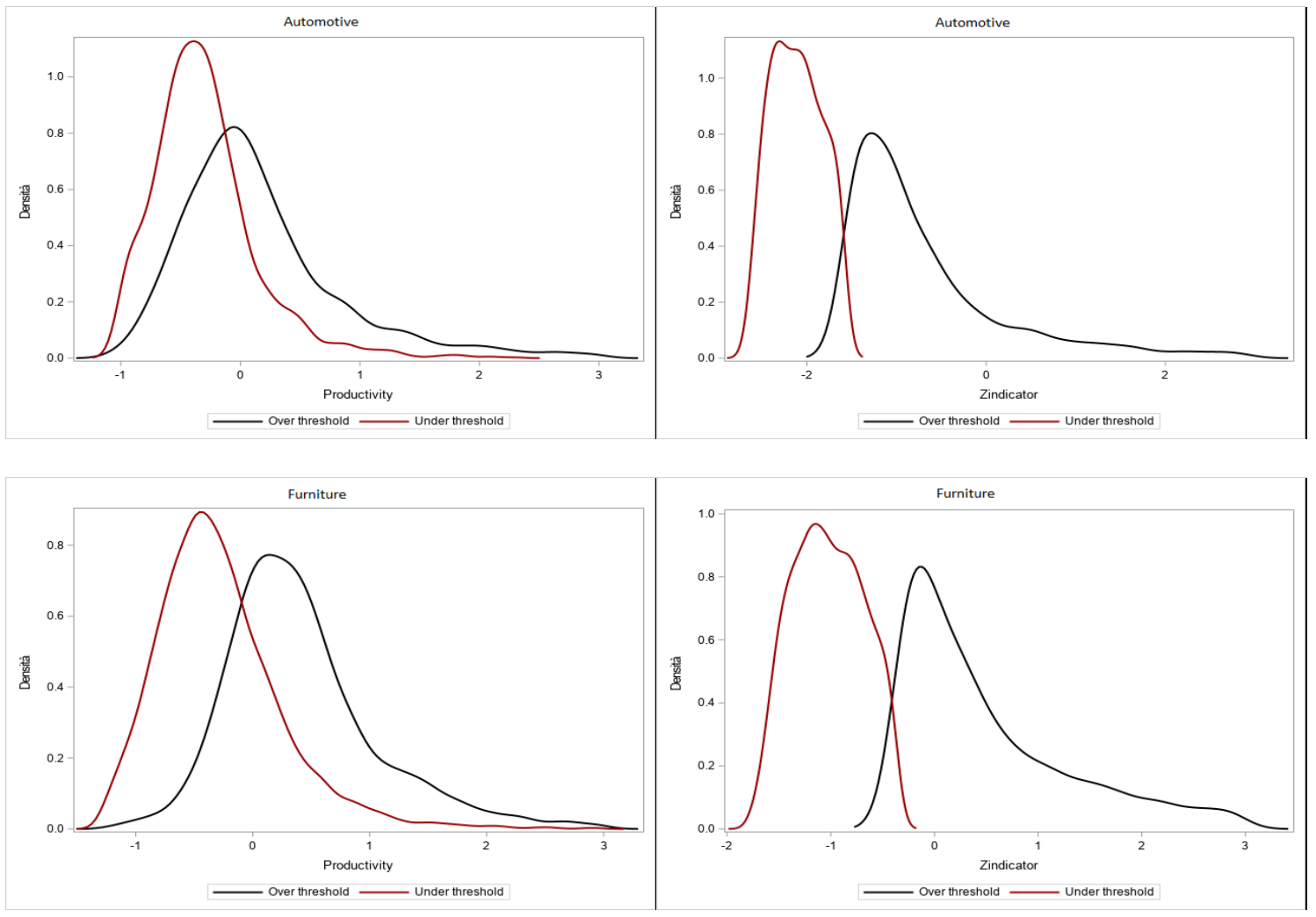
Appendix B. Distance from export threshold and technology line, by industry and taxonomy (median values)

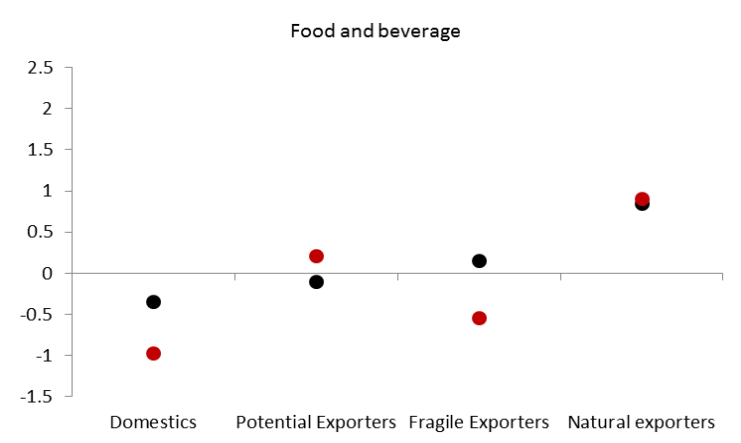

- Distance from export threshold $\quad$ Distance from technology line

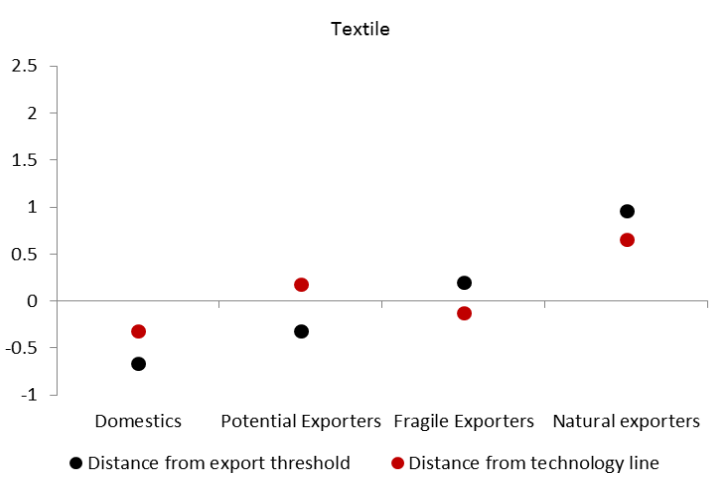

- Distance from export threshold $\quad$ Distance from technology line
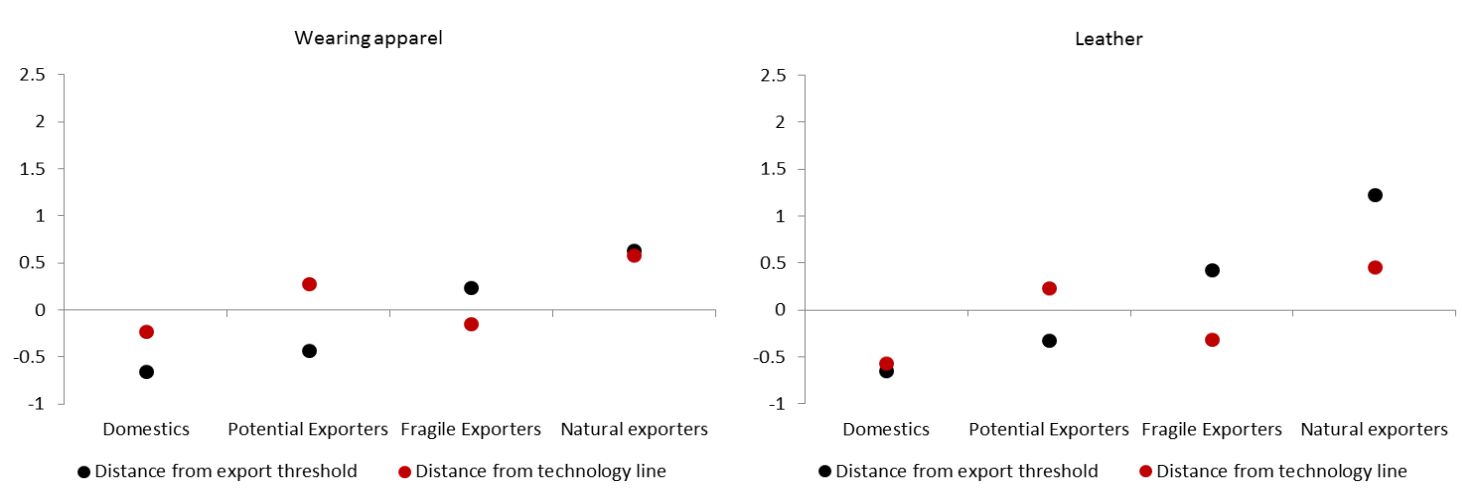

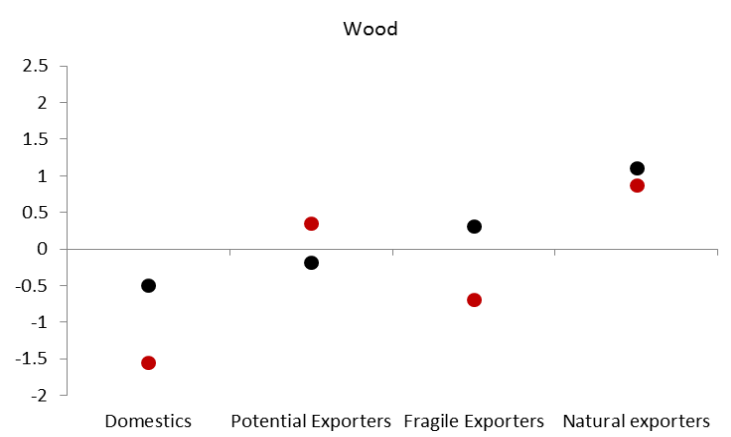

- Distance from export threshold - Distance from technology line

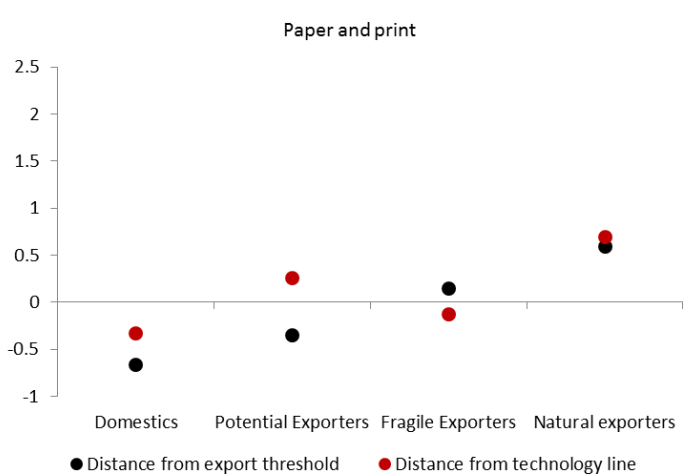



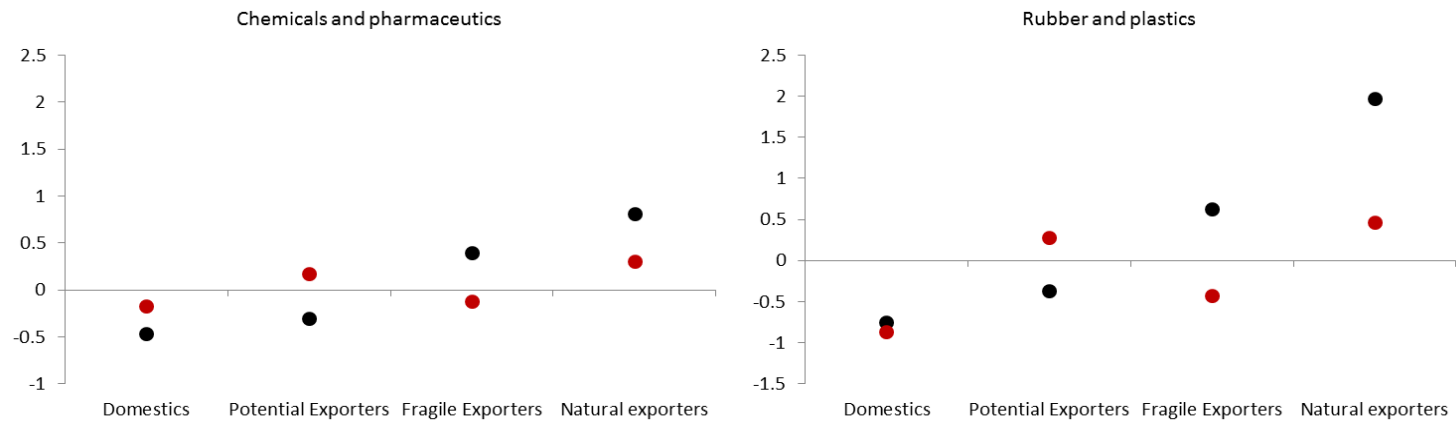

- Distance from export threshold

- Distance from technology line

Non metallic minerals

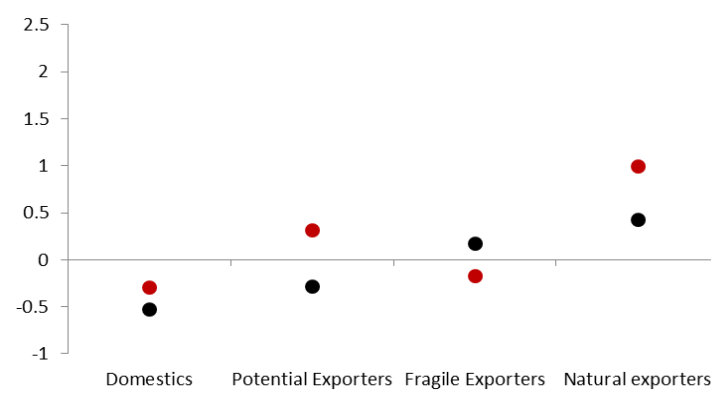

- Distance from export threshold

- Distance from technology line

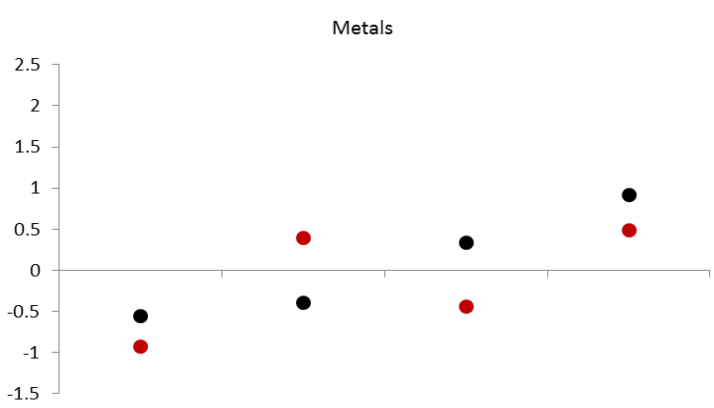

Domestics Potential Exporters Fragile Exporters Natural exporters - Distance from export threshold $\bullet$ Distance from technology line
Electronics

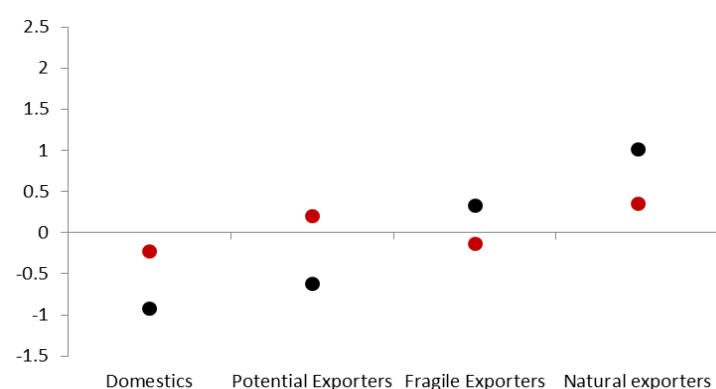

- Distance from export threshold $\quad$ Distance from technology line
Machinery

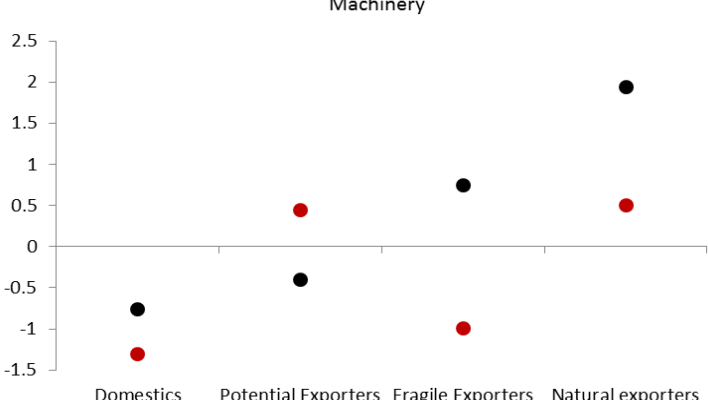

- Distance from export threshold $\bullet$ Distance from technology line
Automotive

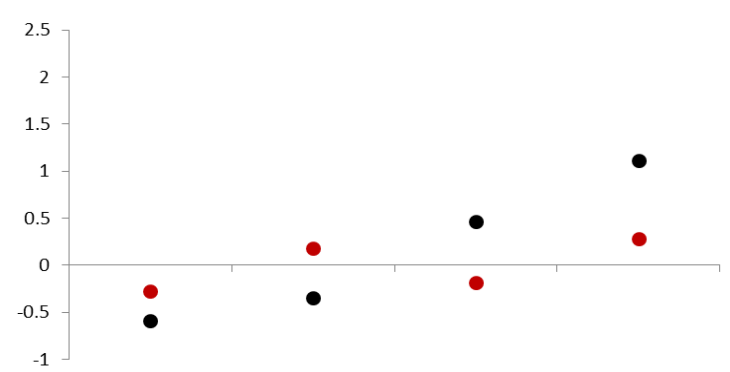

Domestics Potential Exporters Fragile Exporters Natural exporters - Distance from export threshold $\quad$ Distance from technology line

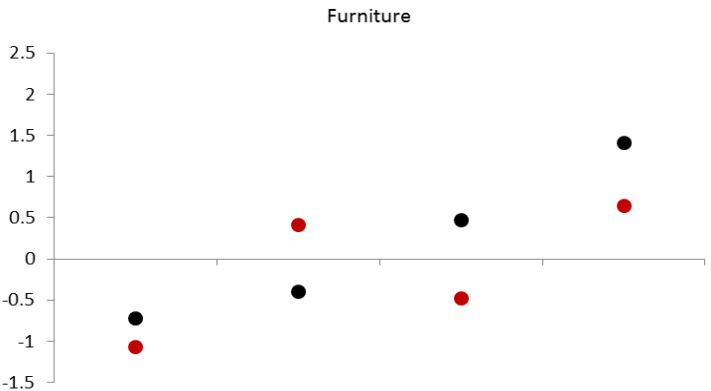

Domestics Potential Exporters Fragile Exporters Natural exporters - Distance from export threshold $\bullet$ Distance from technology line 